DOI: $10.14451 / 1.174 .117$

\title{
ПОКАЗАТЕЛИ ОЦЕНКИ РЕГУЛЯТОРНЫХ РИСКОВ
}

\author{
(c) 2019 Старостин Михаил Геннадьевич \\ Среднерусский институт управления - филиал Российской академии народного хозяйства \\ и государственной службы при Президенте Российской Федерации, Россия, Орел \\ E-mail: os2525@yandex.com
}

Данная статья посвящена изучению показателей оценки регуляторных рисков. Автором обозначены актуальность и значимость темы исследования. Рассмотрена сущность и дано определение термину «показатель оценки регуляторного риска». Предложена классификация показателей оценки регуляторных рисков. Представлены способы ослабления регуляторных рисков. Сделан акцент на важности реализации комплаенс-функции в организации.

Ключевые слова: регуляторный риск, комплаенс-риск, комплаенс-функция, показатели оценки.

Актуальность. В последние годы по всему миру наблюдается резкое увеличение числа правовых требований и требований в сфере комплаенс, затрагивающих деятельность компаний (как небольших, так и крупных). Данный феномен отражает стремительное развитие нормативных ценностей, лежащих в основе регулирования и управления процессами ведения коммерческой деятельности практически любой сферы, а также рост этических ожиданий общества в целом. Это проявилось в целом ряде областей - от законодательства по противодействию взяточничества и коррупции до законодательства об охране окружающей среды, охране труда, защите личных данных и конкуренции. Адаптация к постоянному росту нормативно-правовых требований становится все более сложной задачей для бизнеса и в нашей стране [5, c. 5].

В последние несколько лет проблематика комплаенс-контроля как в российском научном дискурсе, так и практической деятельности предприятий различных сфер и масштабов деятельности, выходит на качественно новый уровень. Все же, в силу молодости института комплаенс-контроля, существует ряд вопросов, касающихся данного элемента организационного менеджмента, отсутствие четких ответов на которые, могут затруднять процесс аналитики и повышать уровень рискогенных факторов. Одним из таких вопросов является подбор показателей и методология оценки регуляторных рисков. Проблематика обусловлена тем, что сам по себе комплаенс-риск не всегда поддается исчислению до момента его возникновения (например, риск потери репутации компании). Важно принимать во внимание, что наличие регуляторных рисков как таковых не является само по себе критичным для предприятия - такие риски обязательно присутствуют, в той или иной степени в любой предпринимательской сфере. Вопрос состоит в том, проводится ли квалифицированная оценка таких рисков, правильно ли подобраны методы, инструменты и показатели оценки, и, как следствие, верные ли рекомендации по минимизации и управлению рисками получает менеджмент организации, выполняются ли такие рекомендации на практике. В целом, недооценка роли аналитических аспектов в системе управления комплаенс-рисками может повлечь за собой их качественный рост.

Выше приведенные аргументы подтверждают актуальность рассмотрение проблемы показателей оценки регуляторных рисков.

Основная часть. Универсальной отправной точкой для предприятия любой сферы и масштабов деятельности является полная концентрация на выявлении организационных рисков, что связано с необходимостью систематической оценки внутренних и внешних факторов, имеющих отношение к деятельности и стратегиям компании, например, экономические и геополитические события, кризис предложения, законодательство (как новое, так и действующее), изменение потребностей и ожидания клиентов, технологические разработки, показатели работы и мотивация персонала и т.п. [7, с. 15]. Названные факторы оказывают динамическое воздействие, в связи с которым в определенных видах предпринимательской деятельности могут возникнуть регуляторные риски.

В документах известной во всем мире консалтинговой и аудиторской компании Deloitte Touche Tohmatsu Limited под регуляторным риском понимается «угроза финансовыми, орга- 
низационными, репутационными позициями организаций, вследствие нарушения законодательства, нормативных актов регулирующих органов, правил поведения, профессиональных стандартов», вследствие чего предприятие теряет возможность быть активным участником рыночных отношений. Считаем данное определение наиболее приемлемым для российской практики, т.к. системно может быть применено к любой сфере коммерческой деятельности и любому бизнес-процессу организации. Так, например, в аспекте инвестиционного проектирования регуляторный риск будет пониматься как угроза инновационно-инвестиционным, экономикофинансовым, прогнозно-организационным и иным позициям предприятия, вследствие нарушения законодательства, нормативных актов регулирующих органов, правил поведения и профессиональных стандартов и стандартов саморегулирующих организаций вследствие которой проект не сможет быть реализован и не принесет прибыли.

Регуляторные риски, как разновидность рисков предпринимательской деятельности, могут проявиться в результате различного рода внешних и внутренних факторов. Наиболее распространенным внешним фактором является несовершенство действующего законодательства РФ. Внутренние факторы регуляторных рисков могут быть различными, например, неэффективная организация деятельности юридического отдела, отдела риск-менеджмента, контрольной или аудиторской деятельности и пр., нарушение договорных условий, несоблюдение требований действующего законодательства непосредственно самой организацией, несоответствие документации законодательным нормам. Однако, в данном контексте, с учетом выявленных факторов наступления регуляторных рисков, они более актуальны для организаций финансового сектора. К сожалению, регуляторные риски, нуждающиеся в достаточной и своевременной оценке, возникают отнюдь не только у финансовых организаций; нефинансовый сектор вынужден также считаться с регуляторными рисками, если компании заинтересованы в том, чтобы сделать свой бизнес эффективным и прибыльным.

С учетом различных научных позиций, peгуляторный риск следует характеризовать как вероятность возникновения некоторых потерь. Оценка регуляторного риска проводится с целью определения размера и вероятности потерь, позволяющих охарактеризовать степень или величину риска. Полагаем, что под показателем оценки регуляторного риска следует понимать соответствующую меру, определяемую посредством аналитических процедур, позволяющую спрогнозировать возможность наступления определенного ущерба, определить потенциальную величину вреда, который может возникнуть в результате некой рисковой ситуации и несвоевременного принятия действий по предотвращению регуляторного риска.

С нашей точки зрения, оценивать регуляторные риски возможно различными методами, принимая во внимание, соответственно, и разнообразные показатели оценки. Нами предлагается показатели оценки регуляторных рисков делить на три группы:

1. Качественные показатели оценки, которые направлены на определение возможных последствий регуляторных рисков, выявление факторов, влияющих на уровень такого риска, а также его потенциальные области. Степень регуляторного риска можно оценить с помощью внешних и внутренних факторов. Так, внешними факторами регуляторного риска являются экономическая и политическая ситуация в стране, правовые основы предпринимательской деятельности, стабильность налоговой системы, конкурентоспособность субъектов хозяйственной деятельности. Внутренние факторы - это экономическая стратегия субъектов хозяйствования, квалификация сотрудников, качество управленческой деятельности, степень и качество использования имеющихся ресурсов.

2. Количественные показатели оценки регуляторного риска предполагают, прежде всего, определение потенциальных размеров данного вида рисков и возможных отрицательных последствий от их наступления. Количественные показатели оценки регуляторного риска можно заключить в соответствующую матрицу регуляторных рисков, которая выступит в качестве фундамента для результативного механизма выявления, мониторинга и ослабления риска. Критерии оценки регуляторного риска - это «маркеры», например, количество судебных дел по искам организации, количество предъявленных претензий, количество судебных дел по искам контрагентов и т.п.

3. Комплексные показатели оценки регуляторного риска учитывают качественные и количественные показатели. Учитывая нестабильность экономической ситуации в нашей стране, 
полагаем, целесообразно, подходить к оценке регуляторного риска именно с позиции использования комплексных показателей. Кроме того, в совокупности, показатели оценки регуляторных рисков позволят выработать методики и подходы к их своевременному смягчению или ослаблению, снижению негативных последствий от возникших регуляторных рисков.

Основываясь на практике кредитных организаций, можно говорить о целесообразности выработки показателей управления регуляторными рисками, основанными, например, на экспертном методе оценки таких событий как:

- прямые финансовые потери (убытки), которые возникают в результате различных нарушений в деятельности сотрудников предприятия (нарушение норм и требований, задокументированных в локальных нормативно-правовых актах, а также внешнем законодательном базиce);

- определение риска возникновения у предприятия убытков по причине несоблюдения федерального, регионального и муниципального законодательства, профильных нормативных документов, а также локальных нормативноправовых актов;

- определения риска возникновения убытков в результате применения санкций и (или) других мер воздействия со стороны контрольнонадзорных органов (например, налоговых органов, органов санитарного или пожарного надзора и т.п.);

- оценка внутренних документов по разработке новых продуктов, работ и услуг, их внедрению и реализации при осуществлении деятельности предприятия;

- анализ экономической целесообразности заключения договоров (В2В, В2С) на производство товаров, исполнение работ или реализацию услуг, обеспечивающих осуществление предприятием своей деятельности;

- жалобы и обращение клиентов, а также иных субъектов внутренней и внешней экосистемы предприятия.

Так, оценивая вероятность (тенденцию) возникновения приведенных событий, можно повысить эффективность управления регуляторными рисками и минимизировать соответствующие их последствия.

Отдельно взятой компании контролировать регуляторный риск на законодательном уровне достаточно сложно, что обусловлено непосредственно масштабностью и объемностью самого риска. Однако, в некоторых ситуациях субъекты хозяйствования могут оказать непосредственное воздействие на митигацию регуляторного риска. Учитывая предложенную выше классификацию показателей оценки регуляторных рисков, предлагаем следующие способы адаптации предпринимателей в условиях возникновения регуляторного риска:

1. Реактивный способ, позволяющий субъектам хозяйствования не предпринимать никаких действий до момента, пока не будет принят регулирующий правовой акт, и лишь после этого осуществить его анализ, действуя, в дальнейшем, по ситуации. С нашей точки зрения, данный способ - крайняя мера реагирования на возникший регуляторный риск. Например, после введения российским Правительством санкций на импорт отдельных категорий товаров из стран Европейского союза и США, некоторые предприниматели были вынуждены использовать исключительно реактивный способ митигации данного регуляторного риска, т.к. не были готовы к подобным событиям.

2. Универсальный (стабильный) способ дает субъекту хозяйствования некоторый запас времени и выбор действий в случае возникновения регуляторного риска. Так, экономический субъект может предварительно провести анализ нормативного правового акта, разрабатывая при этом стратегию поведения, обновляя её по мере внесения изменений и дополнений в правовой документ, а также своевременно реагируя на перемены. Например, данный способ митигирования может оказаться весьма полезным в рамках законодательных нововведений, касающихся самозанятости. Данный проект будет реализован на добровольных началах, на уровне четырех субъектов федерации, в течение достаточно продолжительного времени (до 2028 г.).

3. Превентивный способ - полагаем, один из наиболее оптимальных способов митигации регуляторных рисков, который позволяет в полной мере оценить и выявить все показатели регуляторного риска, предварительно принять меры ещё на этапе разработки нормативного правового акта.

Вне зависимости от сферы и масштаба деятельности, этапа бизнес-процессов предприятия, регуляторный риск, равно как и любой другой должен быть управляем. В основе комплаенс-менеджмента, безусловно, лежат известные процедуры управления рисками, которые разрабатывались учеными на протяже- 
нии многих десятилетий, а также включены в тексты международных нормативно-правовых актов, стандартов по внутреннему контролю и управлению рисками. В зарубежной литературе, управление комплаенс-рисками как деятельность носит название комплаенс-функция. В целом, она помогает руководству предприятия построить эффективную систему внутреннего контроля и управления регуляторными рисками, оптимально встроенную в систему корпоративного управления для максимально эффективного и результативного осуществления ими функций по управлению организацией, контролю за бизнес-процессами и выполнению обязательств перед всеми субъектами экосистемы предприятия или корпорации. Как актуально отмечает А.Г. Терехов, комплаенс - это обязательная составляющая системы управления; он формирует фундамент контроля любой организации, всегда функционирующей по тем или иным правилам $[6$, c. 14$]$.

Вопросы методологического обеспечения деятельности в области такого элемента данной системы управления, как оценка комплаенсрисков должны, соответственно, решаться внутренними структурами предприятий. Коммуникативные процессы по данному вопросу могут быть организованы, например, между финансовым отделом (отделом по управлению рисками или отделом по аудиту) и юридическим отделом, специализирующимся на вопросах отраслевого права. Однако, все же, многое зависит от вида комплаенс-риска. Так, например, департамент комплаенс является владельцем следующих видов рисков: риски нарушения антикоррупционных требований и процедур, этические риски, риски, связанные с маркетингом продукции (например, предоставление полной и частной информации в отношении фармацевтических продуктов), риски, связанные с защитой персональных данных и т.п. [3, с. 9]. Подобный подход может привести к значительной оптимизации методов работы предприятия с комплаенсрисками в той связи, что работа в данном направлении, будет осуществляться за счет тех же ресурсов и опыта, благодаря чему появится «взаимоподкрепляющая» структура. В случае, если в силу избранной в организации организационноуправленческой структуры между рабочими группами по управлению комплаенс-рисками существует мало связей, целесообразно изучить вопрос о принятии мер для достижения назван- ной цели в будущем.

Выводы. В рамках проведённого исследования особое внимание уделено оценке регуляторных рисков и градации показателей, позволяющих своевременно оценить масштабы данного вида рисков, принять надлежащие действия по его ослаблению. Под показателем оценки регуляторного риска следует понимать соответствующую меру, определяемую посредством аналитических процедур, позволяющую спрогнозировать возможность наступления определенного ущерба, определить потенциальную величину вреда, который может возникнуть в результате некой рисковой ситуации и несвоевременного принятия действий по предотвращению регуляторного риска. На наш взгляд, показатели оценки регуляторных рисков следует рассматривать дифференцированно. В исследовании выделены качественные, количественные и комплексные показатели оценки регуляторных рисков. Также выдвинуто предположение о том, что посредством экспертных методов оценки, связанных с регуляторикой событий в организации можно повысить эффективность управления регуляторными рисками и минимизировать соответствующие их последствия.

С учетом сформулированных показателей оценки и их содержания, определены три способа ослабления действия регуляторных рисков (универсальный, реактивный и превентивный способ реагирования), которые могут оказаться полезными на практике для различных субъектов хозяйствования.

Итак, институт регуляторных рисков на современном этапе уже в достаточной степени адаптирован к экономическим и экономикополитическим реалиям, в которых находится отечественный бизнес-сектор. Соответствующие регуляторные риски, после их выявления, целесообразно дополнительно оценить для установления вероятности наступления каждого из них, а также его предполагаемого воздействия. Кроме того, поддерживая точку зрения В.Е. Понамаренко и А.Р. Корнилова, отметим, что актуализация концепта комплаенс способствует реализации в национальных правовых системах международного «мягкого» права, ориентированного на комплексное регулирование экономической деятельности, что отражается во внедрении комплексных и межотраслевых процедур контроля соблюдения различного рода правил самими субъектами хозяйствования [4]. 


\section{Библиографический список}

1. Положение об организации внутреннего контроля в кредитных организациях и банковских группах, утв. Банком России 16.12.2003 № 242-П (ред. от 04.10.2017) // Вестник Банка России. - № 7.- 2004.

2. Письмо Банка России от 30.06.2005 № 92-Т «Об организации управления правовым риском и риском потери деловой репутации в кредитных организациях и банковских группах» // Вестник Банка России. - № 34. 2005.

3. Международное исследование функций комплаенс // КПИГ в России и СНГ. - 2016. - 22 с.

4. Понаморенко B.Е., Корнилов А.Р. О практиках мониторинга имплементации глобальных финансовых стандартов в национальные правовые системы // Актуальные проблемы и перспективы развития экономики: труды Юбилейной XV международной научно-практической конференции. Симферополь - Гурзуф, 17-19 ноября 2016.- С. 170-174

5. Практическое пособие ICC по антимонопольному комплаенсу. Практические меры по соблюдению антимонопольного законодательства для малых и средних предприятий и крупных компаний.- Международная торговая палата (ICC).-2013.- 105 с.

6. Трансформация комплаенса и риск-менеджмента в системе внутреннего контроля / А.Г. Терехова // Внутренний контроль в кредитной организации. - 2011.- № 1.- С. 13-16.

7. Чернова Г.В. Страхование и управление рисками.-М.: Издательство Юрайт. 2014. - 768 с. 